OPEN ACCESS

Edited by:

Wan-Uk Kim,

Catholic University of Korea,

South Korea

Reviewed by:

Je-Min Choi,

Hanyang University, South Korea

Nadia Maria Terrazzini,

University of Brighton,

United Kingdom

*Correspondence:

Gustavo J. Martinez

gustavo.martinez@rosalindfranklin.edu

Specialty section: This article was submitted to Inflammation,

a section of the journal

Frontiers in Immunology

Received: 26 October 2018

Accepted: 21 January 2019

Published: 15 February 2019

Citation:

Xu T, Keller A and Martinez GJ (2019) NFAT1 and NFAT2 Differentially

Regulate CTL Differentiation Upon Acute Viral Infection.

Front. Immunol. 10:184. doi: 10.3389/fimmu.2019.00184

\section{NFAT1 and NFAT2 Differentially Regulate CTL Differentiation Upon Acute Viral Infection}

\author{
Tianhao Xu, Ashleigh Keller and Gustavo J. Martinez* \\ Department of Microbiology and Immunology, Chicago Medical School, Rosalind Franklin University, North Chicago, IL, \\ United States
}

$\mathrm{CD}^{+} \mathrm{T}$ cell differentiation orchestrated by transcription regulators is critical for balancing pathogen eradication and long-term immunity by effector and memory CTLs, respectively. The transcription factor Nuclear Factor of Activated T cells (NFAT) family members are known for their roles in T cell development and activation but still largely undetermined in $\mathrm{CD}^{+}{ }^{+} \mathrm{T}$ cell differentiation in vivo. Here, we interrogated the role of two NFAT family members, NFAT1 and NFAT2, in the effector and memory phase of $\mathrm{CD}^{+} \mathrm{T}$ cell differentiation using LCMVArm acute infection model. We found that NFAT1 is critical for effector population generation whereas NFAT2 is required for promoting memory CTLs in a cell intrinsic manner. Moreover, we found that mice lacking both NFAT1 and NFAT2 in T cells display a significant increase in KLRG1 ${ }^{\text {hi }}$ CD127 ${ }^{\text {hi }}$ population and are unable to clear an acute viral infection. NFAT-deficient CTLs showed different degrees of impaired IFN- $\gamma$ and TNF- $\alpha$ expression with NFAT1 being mainly responsible for IFN- $\gamma$ production upon ex-vivo stimulation as well as for antigen-specific cytotoxicity. Our results suggest that NFAT1 and NFAT2 have distinct roles in mediating CD8 ${ }^{+}$T cell differentiation and function.

Keywords: NFAT1, NFAT2, CD8 ${ }^{+}$T cells, differentiation, effector, memory, LCMV

\section{INTRODUCTION}

$\mathrm{CD}^{+} \mathrm{T}$ cells are pivotal in combating intracellular pathogens and for tumor immune surveillance $(1,2)$. Upon recognizing their cognate antigen presented by antigen-presenting cells (APCs), naïve $\mathrm{CD}^{+}{ }^{+} \mathrm{T}$ cells are activated, rapidly proliferate and differentiate into a heterogeneous pool of effector cells which display cytotoxic activity (3). The heterogeneity of activated CD8 ${ }^{+} \mathrm{T}$ cells has been characterized by the expression of different surface markers and transcription factors. Conventionally, effector cells are further categorized into two main subsets: short-lived effector $\mathrm{T}$ cells (SLECs) as KLRG1 ${ }^{\text {hi }} \mathrm{CD} 127^{\mathrm{lo}}$ and memory precursor effector cells (MPECs) as KLRG1 ${ }^{\text {lo }}$ $\mathrm{CD} 127^{\mathrm{hi}}$ (4). Upon clearance of the pathogen or tumor, most antigen-specific SLECs die due to lack of antigen stimulation. The remaining MPECs are responsible for providing long-term protection upon subsequent reinfections $(4,5)$. A recent study shows that SLECs could also contribute to part of the memory population pool, demonstrating CTLs' plasticity (6).

The dynamic $\mathrm{CD}^{+} \mathrm{T}$ cell terminal effector and memory differentiation balance and heterogeneity is orchestrated by transcription regulators, many of which are still unidentified. The transcription factors Tbet and Eomesodermin (Eomes) have long been known to directly control CD $8^{+} \mathrm{T}$ cell effector and memory differentiation, respectively $(7,8)$. In recent years, other 
transcription factors have been identified to regulate CTL differentiation: Id 2 and Blimp-1 are critical for effector CTL formation while Id3, Bcl-6, Tcf-1, and Runx3 are cardinal for memory $\mathrm{CD}^{+} \mathrm{T}$ cell development (8-12). The b-zip transcription factor BATF is required for early TCR signaling amplification and partnering with other transcription factors, such as JUN and IRF4 (13-16). Runx3, a transcription factor responsible for mediating $\mathrm{CD}^{+} \mathrm{T}$ cell commitment in the thymus by antagonizing ThPok, which drives $\mathrm{CD} 4^{+}$Th cell fate (17), has been also recently implicated in the early TCR signaling events during priming to promote the accessibility of chromatin containing IRF, bZIP, and PRDM1 binding motifs resulting in the strengthening of memory population differentiation (18). Despite the knowledge on how these transcription factors regulate CTL differentiation in vivo, the exact mechanisms that set off the effector and memory $\mathrm{CD}^{+} \mathrm{T}$ cells development are still unclear, especially those transcription factors downstream of early TCR signaling events.

Nuclear factor of activated T cells (NFAT) is a well-known transcriptional regulator of $\mathrm{T}$ cell activation and plays an essential role in $\mathrm{T}$ cell development, activation and function. There are five NFAT family members, among them, NFAT1, NFAT2, and NFAT4 are expressed in T cells downstream of $\mathrm{Ca}^{2+}$-Calcineurin signaling (19). All NFAT members share a consensus DNA binding motif which allows them to bind to the same DNA sequence (20-22). Upon T cell activation, NFAT is dephosphorylated and rapidly translocates into the nucleus to regulate gene expression via cooperation with other transcriptional regulators $(21,23)$. Recent studies have shown that different NFAT members have distinct properties and roles in $\mathrm{CD}^{+}{ }^{+} \mathrm{T}$ lymphocytes, especially in $\mathrm{Th} 1$, Th17, Tfh, and Tregs (24-26). In vitro study of $\mathrm{CD}^{+} \mathrm{T}$ cells selectively deficient in NFAT1, NFAT2, or NFAT4 and/or combination demonstrated a distinct role of these transcription factors regulating cytokines and inhibitory receptors expression (27). However, the distinction among NFAT members establishing $\mathrm{CD}^{+} \mathrm{T}$ cell effector and memory differentiation in vivo is still undetermined.

In this study, we examined the role of NFAT1 and NFAT2 in CTL differentiation and function using an acute lymphocytic choriomeningitis virus Armstrong strain (LCMV $\left.{ }^{A r m}\right)$ infection model $(28,29)$. We characterized LCMV-specific $\mathrm{CD}^{+} \mathrm{T}$ cell effector and memory population in mice deficient in NFAT1, mice with $\mathrm{T}$ cell-specific NFAT2 deficiency or with double deficiency of NFAT1 and NFAT2 in T cells. We found that NFAT1 is required for effector while NFAT2 is necessary for memory population generation. Mice deficient in both NFAT1 and NFAT2 have delayed memory differentiation and are unable to control an acute viral infection. Moreover, we also observed reduced cytokine production in all NFATdeficient cells, with cells deficient in both transcription factors having the strongest effect, as well as an imbalanced Tbet and Eomes expression. The defect in CTL differentiation was cellintrinsic, as evidenced by both mixed bone marrow chimera experiments and adoptive transfer of NFAT-deficient antigenspecific P14 TCR transgenic cells. These results suggest that NFAT1 and NFAT2 are indispensable and have distinct roles in initiating $\mathrm{CD}^{+} \mathrm{T}$ cell effector and memory differentiation and function.

\section{MATERIALS AND METHODS}

\section{Mice}

All mice from C57BL/ 6 background used in the experiments were 6-8 weeks old, sex, and age matched. NFAT $1^{-/-}$and $\mathrm{NFAT} 2^{\mathrm{fl} / \mathrm{fl}}$ CD4-Cre and $\mathrm{NFAT}^{-/-} \mathrm{NFAT} 2^{\mathrm{fl} / \mathrm{fl}}$ CD4-Cre mice were obtained from La Jolla Institute for Allergy and Immunology (LJI, San Diego, CA) and have been described (24). NFAT1 ${ }^{-/}-$mice were crossed with $\mathrm{NFAT} 2^{\mathrm{fl} / \mathrm{fl}} \mathrm{CD} 4-\mathrm{Cre}{ }^{+}$to generate $\mathrm{NFAT}^{-/-}$ NFAT2 ${ }^{\mathrm{fl} / \mathrm{fl}}$ CD4-Cre ${ }^{+}$(NFAT1/2 DKO) mice. P14 Thy1.1 or P14 TCR $\alpha^{-/-}$TCR transgenic mice were further crossed with NFAT deficient mice described above. For the mixed bone marrow chimera experiment, bone marrow cells were isolated from tibia and femur from B6.SJL CD45.1 mice, and mixed 1:1 ratio with bone marrow cells from C57BL/6 CD45.2 WT, $\mathrm{NFAT}^{-/}{ }^{-}$, NFAT2 ${ }^{\mathrm{fl} / \mathrm{fl}} \mathrm{CD} 4-\mathrm{Cre}^{+}$, and NFAT1 ${ }^{-/-} \mathrm{NFAT}^{\mathrm{fl} / \mathrm{fl}}$ CD4-Cre ${ }^{+}$mice. Then, 7 million mixed bone marrow cells were transferred into lethally irradiated recipient B6SJL mice. All mice were maintained in specific-pathogen-free barrier facilities and used according to protocols approved by the Rosalind Franklin University of Medicine and Science Institutional Animal Care and Use Committee (IACUC).

\section{Lymphocytic Choriomeningitis Virus (LCMV) Models}

WT, NFAT1 ${ }^{-/-}\left(\right.$NFAT1 KO), NFAT2 ${ }^{\mathrm{fl} / \mathrm{fl}} \mathrm{CD}^{-} \mathrm{Cre}^{+}$(NFAT2 $^{-}$ TKO), or $\mathrm{NFAT}^{-/-}$, NFAT2 ${ }^{\mathrm{fl} / \mathrm{fl}} \mathrm{CD} 4 \mathrm{Cre}^{+}$(NFAT1/2 DKO), as well as mixed bone marrow chimera mice were infected intraperitoneally (i.p) with $2 \times 10^{5}$ PFU of LCMV Armstrong $\left(\mathrm{LCMV}^{\mathrm{Arm}}\right)$ kindly provided by Dr. Shane Crotty at LJI. After infection, splenocytes, and serum were harvested. Serum viral titers were measured by plaque assay as described (29).

\section{Cell Staining and Flow Cytometry}

Single cell suspension isolated from spleens or heparinized blood were treated with RBC lysis buffer, washed and incubated with tetramer and antibody cocktails for surface staining. Single cell suspensions were initially incubated with LCMV tetramers H2D ${ }^{\mathrm{b}}-\mathrm{GP} 33-41$ (KAVYNFATC) Alexa647, H2D ${ }^{\mathrm{b}}$ GP276-286 (SGVENPGGYCL) BV421, and H2D ${ }^{\mathrm{b}}$-NP396-404 (FQPQNGQFI) PE kindly obtained from the NIH Tetramer Facility, followed by staining of cell surface molecules including CD44, CD4, B220, CD8, KLRG1, CD127, and CXCR3. For intracellular transcription factor and cytokine staining, cells were then fixed, permeabilized and stained with antibody against Tbet, Eomes, IFN- $\gamma$, TNF- $\alpha$, using eBioscience intracellular staining kits. Expression of these markers was assessed by flow cytometry using BD LSRII. The antibodies and reagents used are listed in Supplementary Table 1.

\section{T Cells Isolation, Culture, Cytokine Production, and Cytotoxicity Assay}

Spleen and lymph nodes were harvested, naïve $\mathrm{CD} 8^{+}$cells were purified using Stem Cell EasySep kit from pooled spleen and 
lymph node cells. Dulbecco's modified Eagle's medium (DMEM) supplemented with $10 \%$ heat-inactivated fetal bovine serum, $2 \mathrm{mM}$ L-glutamine, penicillin-streptomycin, non-essential amino acids, sodium pyruvate, vitamins, $10 \mathrm{mM}$ HEPES, and $50 \mathrm{uM}$ 2 -mercaptoethanol were used for T cell culture (24). Cells $\left(10^{6}\right.$ cells $/ \mathrm{ml}$ ) were stimulated with anti-CD3 (clone3 2C11) and antiCD28 (clone 37.51) $(1 \mu \mathrm{g} / \mathrm{ml}$ each, both from BioXcell), $2 \mathrm{U}$ IL-2 and $50 \mathrm{ng} / \mathrm{ml}$ gentamycin in 6-well plates that had been pre-coated with $50 \mu \mathrm{g} / \mathrm{ml}$ goat anti-hamster IgG (Pierce, Life Technologies). On day 2, cells were removed from the initial stimulus, and cultured at 0.5 million cells $/ \mathrm{ml}$ with $10 \mathrm{U} / \mathrm{ml}$ of recombinant human IL-2 (30).

To assess cytokine production and the cytotoxicity activity, on day 6 after activation, cells were co-cultured at different ratios with GFP-expressing parental mammary carcinoma cell line EO771 (negative control to determine non-specific target lysis), or EO771 cells expressing the cognate antigen GP3341 (kindly provided by Mark Sundrud at TSRI-FL). After $12 \mathrm{~h}$ incubation, remaining live GFP-expressing EO771 cells were determined by FACS as a measurement of cytotoxic activity. GP33-41-expressing EO771 cells cultured in the absence of CTL were used as baseline for cell death. Cytokine production was also measured upon restimulation with PMA and Ionomycin or with RAG1 ${ }^{-/-}$splenocytes incubated with $0.2 \mu \mathrm{g} / \mathrm{ml}$ of GP33-41 peptide for $4 \mathrm{~h}$ in the presence of BrefeldinA.

\section{Quantitative Real-Time RT-PCR}

Total RNA was prepared from $\mathrm{T}$ cells after stimulation using TRIzol reagent (Invitrogen). cDNA was synthesized using Superscript reverse transcriptase and oligo(dT) primers (Invitrogen), and gene expression was examined with 7900 Real Time PCR System (Applied Biosystems) using Power SYBR green PCR Master Mix (Thermo Fisher). Gene expression was normalized to Rpl32 (encodes L32 ribosomal protein) gene expression. The following primers were utilized: Rpl32 forward: 5'-CGTCTCAGGCCTTCAGTGAG-3'; Rpl32 reverse: $5^{\prime}$-CAA GAGGGAGAGCAAGCCTA-3'; Ifng forward: 5'-ATCTGGAG GAACTGGCAAAA-3'; Ifng reverse: 5'-TTCAAGACTTCA AAGAGTCTGAGGTA-3'; Il2 forward: 5'-TTGTGCTCCTT GTCAACAGC-3'; Il2 reverse: 5'-CTGGGGAGTTTCAGGT TCCT-3'; Tnf forward: $5^{\prime}$-GCCTCTTCTCATTCCTGCTTG-3'; Tnf reverse: $5^{\prime}$-CTGATGAGAGGGAGGCCATT-3'; Gzmb forward: 5'-CCACTCTCGACCCTACATGG- ${ }^{\prime}$; Gzmb reverse: 5'-GGCCCCCAAAGTGACATTTATT-3'; Prf1 forward: 5' -AAT ATCAATAACGACTGGCGTGT-3'; Prf1 reverse: 5'-CATG $^{\prime}$ TTTGCCTCTGGCCTA- $3^{\prime}$.

\section{Statistics and Analysis}

Flow cytometry data was analyzed with FlowJo (Version 9.9.4). Graphs are plotted using Prism 7 graph pad. Statistical analysis was performed using non-paired One-Way ANOVA followed by Tukey's multiple comparisons, unpaired two-tailed $t$-test or TwoWay ANOVA followed by Dunnett comparisons. Correlation test was done using the non-parametric Spearman correlation coefficient. ${ }^{*} p \leq 0.05,{ }^{* *} p \leq 0.01,{ }^{* * *} p \leq 0.001,{ }^{* * * *} p \leq 0.0001$.

\section{RESULTS}

\section{NFAT1 and NFAT2 Distinctively Regulate CD8 $^{+}$T Cell Effector and Memory Differentiation During Acute LCMVArm Infection}

To examine the role of NFAT1 and NFAT2 in $\mathrm{CD}^{+} \mathrm{T}$ cell differentiation during acute viral infection, we used mice deficient in NFAT1 (NFAT1 ${ }^{-/-}$, referred as NFAT1 KO) and mice with conditional $\mathrm{T}$ cell-specific deficiency of NFAT2 $\left(\mathrm{NFAT} 22^{\mathrm{f} / \mathrm{fl}} \mathrm{CD} 4-\mathrm{Cre}^{+}\right.$, referred herein as NFAT2 TKO). We bred NFAT1KO mice with NFAT2 TKO mice to generate NFAT1 ${ }^{-/-}$ $\mathrm{NFAT2}^{\mathrm{fl} / \mathrm{fl}} \mathrm{CD}$-Cre ${ }^{+}$(hereafter mentioned as NFAT1/2 DKO) mice. Six to eight weeks old WT, NFAT1 KO, NFAT2 TKO, and NFAT1/2 DKO mice were intraperitoneally injected with $\mathrm{LCMV}^{\text {Arm }}$. Eight days post-infection, corresponding to the peak of the $\mathrm{T}$ cell effector response, we characterized the generation of $\mathrm{CD}^{+} \mathrm{T}$ cell effector and memory antigen-specific populations using LCMV H2D ${ }^{\mathrm{b}}$-GP33-41 tetramer staining (Figures 1A,B, S1). We found that NFAT1 KO mice have increased spleen cellularity, whereas NFAT2 TKO and NFAT1/2 DKO mice have significant fewer splenocytes compared to WT controls (Figure S1B). NFAT1/2 DKO mice also displayed significantly lower percentage and number of antigen-specific $\mathrm{CD}^{+}{ }^{+} \mathrm{T}$ cells (LCMV tetramer $\mathrm{H}_{2} \mathrm{D}^{\mathrm{b}}-\mathrm{GP} 33-41^{+}$) compared to their WT counterparts (Figures 1A,B, S1E). Moreover, NFAT2 TKO and NFAT1/2 DKO mice exhibit lower number of $\mathrm{CD} 8^{+} \mathrm{T}$ cells in spleen (Figures S1C,D).

To evaluate the effect of deficiency in distinct NFAT members in CTL differentiation, we determined the SLECs, MPECs and effector memory (KLRG1 ${ }^{\text {hi }} \mathrm{CD} 127^{\text {hi }}$ ) populations on antigen-specific $\mathrm{CD} 8^{+} \mathrm{T}$ cells recognizing GP33-41 peptide of LCMV. NFAT1 KO mice exhibit a significantly decreased SLEC population and an increase in $\mathrm{CD} 127^{\text {hi }}$ cells, with over 3-fold increase in effector memory and MPEC populations compared to WT controls (Figures 1C,D). On the contrary, NFAT2 TKO mice displayed an increase in KLRG1-expressing cells, particularly the effector memory subset, while NFAT1/2 DKO mice had a significant increase in effector memory cells expressing both KLRG1 and CD127, suggesting an additive effect of NFAT1 and NFAT2 deficiency. To exclude that the phenotype observed was specific only to LCMV H2D ${ }^{\mathrm{b}}$-GP33-41 tetramer, we additionally evaluated the CTL differentiation in $\mathrm{H}_{2} \mathrm{D}^{\mathrm{b}}-\mathrm{GP} 276-286$ and $\mathrm{H}_{2} \mathrm{D}^{\mathrm{b}}$-NP396-404 specific CD8 ${ }^{+} \mathrm{T}$ cells (Figures S1F,G). We observed that each and combined NFAT deficiency led to an altered effector/memory CTL differentiation as described above irrespective of the antigen specificity.

The expression of the chemokine receptor CXCR3 is upregulated during $\mathrm{CD}^{+} \mathrm{T}$ cell activation, and maintained through the transition from effector to memory population, though it remains at higher levels in memory CD27 hi CTLs (3133). CXCR3 is important for trafficking of CTLs to peripheral tissues and lymphoid compartments allowing for the interaction with antigen-presenting cells, and further sustaining a type-1 inflammatory response (32). Using this marker, we also found a differential generation of KLRG ${ }^{\text {lo }}$ CXCR ${ }^{\text {hi }}$ and KLRG1 ${ }^{\text {hi }}$ CXCR $^{\text {hi }}{ }^{2}$ populations upon NFAT1 or NFAT2 deficiency 
A

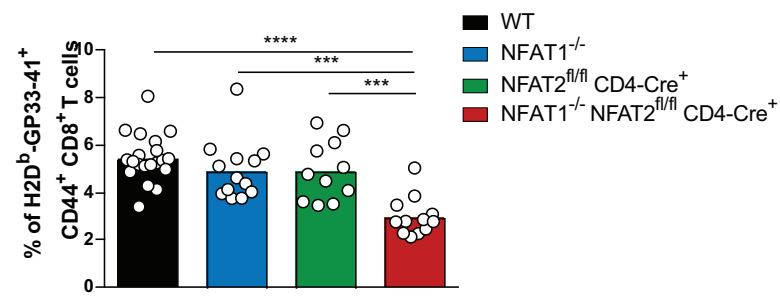

B
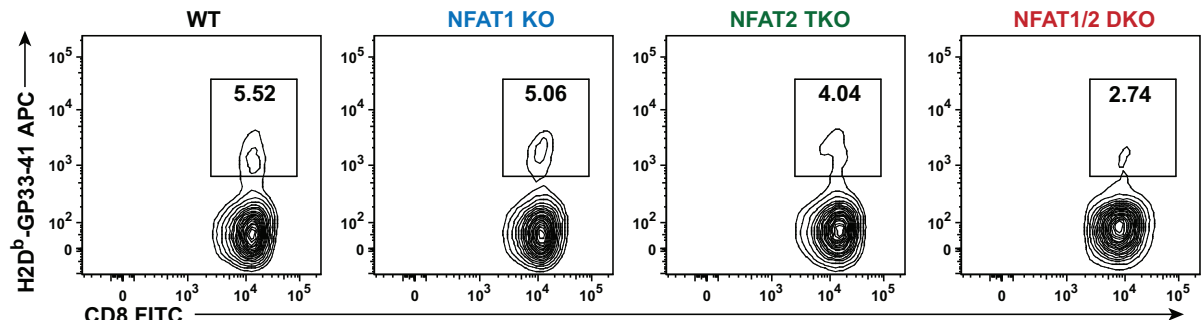

C
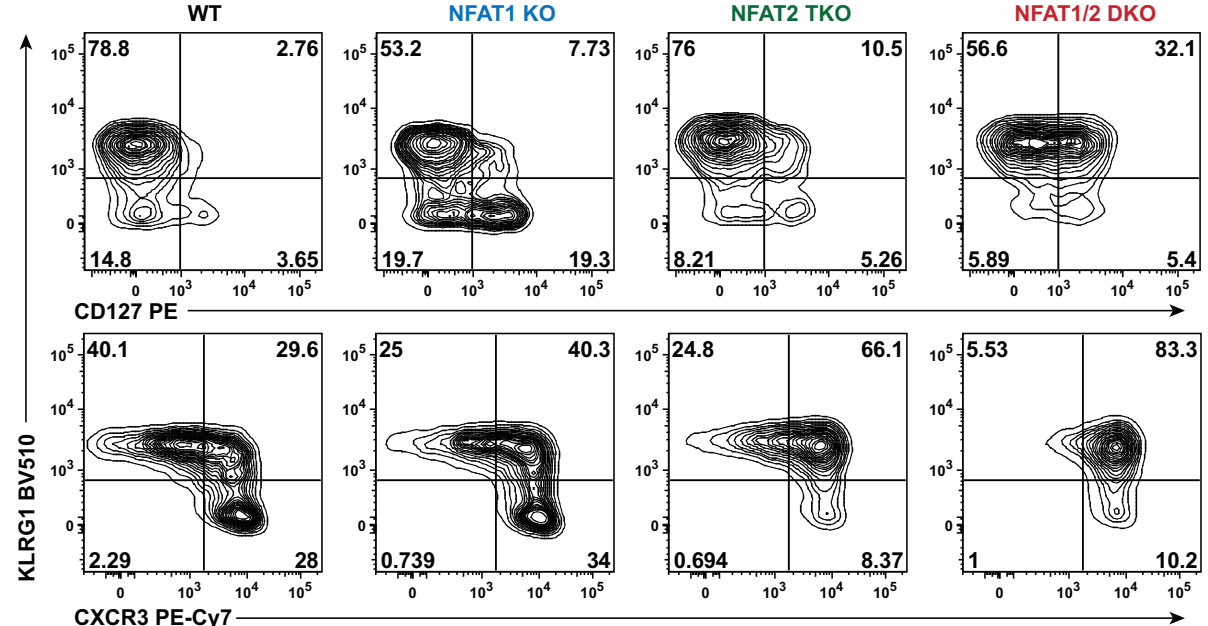

D
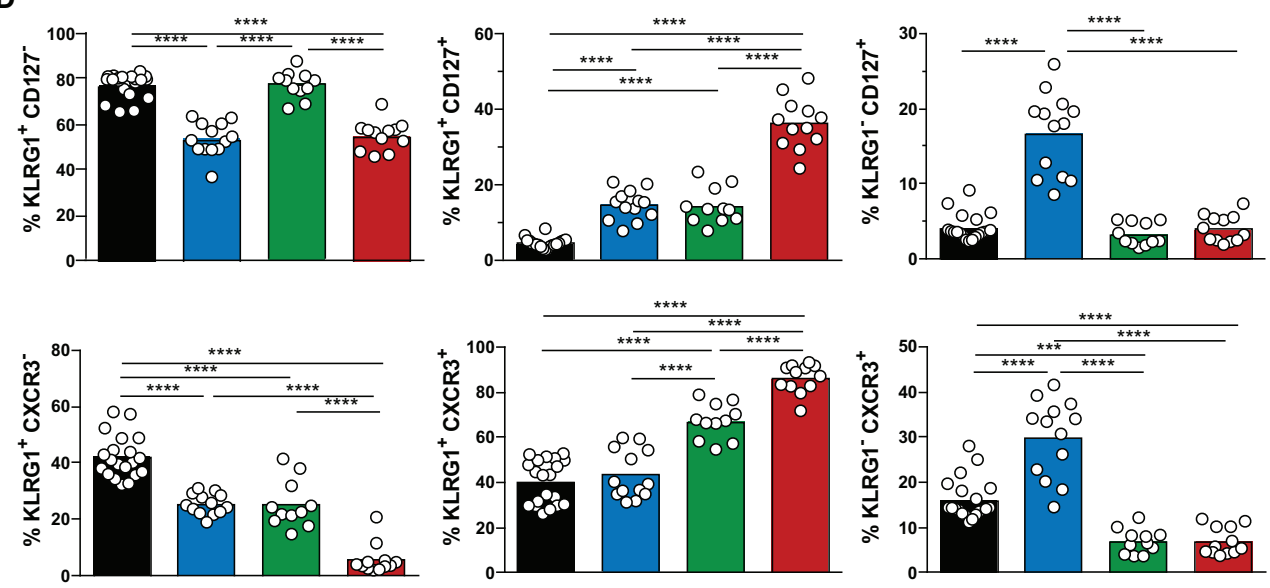

FIGURE 1 | NFAT1 and NFAT2 distinctively regulate CD8 ${ }^{+}$T cell effector and memory differentiation during acute LCMVArm infection. Mice were infected with LCMV Arm $\left(2 \times 10^{5} \mathrm{PFU} / \mathrm{mouse}\right)$ intraperitoneally (i.p.). Spleens were harvested on day 8 after infection, and phenotypic characterization of CD ${ }^{+} \mathrm{T}$ cells was performed. $(\mathbf{A}, \mathbf{B})$ Frequency of $\mathrm{H}_{2} \mathrm{D}^{\mathrm{b}}$-gp33-41+ (LCMV-specific) cells gated on CD8 ${ }^{+} \mathrm{CD} 44^{\text {hi }} \mathrm{CD}^{-}{ }^{-} \mathrm{B} 22 \mathrm{O}^{-}$splenocytes were determined, and presented as the combined data from three independent experiments $\mathbf{( A )}$ or a representative contour plot (B). (C,D) Expression of KLRG1, CD127, and CXCR3 gated on H2D ${ }^{\mathrm{b}}$-gp33-41 ${ }^{+} \mathrm{CD}^{+}$ $\mathrm{CD}_{4}{ }^{\mathrm{hi}} \mathrm{CD}^{-}{ }^{-} \mathrm{B} 220^{-}$cells was determined as a representative contour plot (C) and pooled data from three independent experiments (D). (A,D) Statistical analysis was performed on three independent experiments combined using non-paired One-Way ANOVA followed by Tukey's multiple comparisons. ${ }^{\star} p \leq 0.05$, ${ }^{\star \star} p \leq 0.01$, ${ }^{* * *} p \leq 0.001,{ }^{* * * *} p \leq 0.0001$. 
(Figures 1C,D). Moreover, NFAT1/2 DKO mice have more than eighty percent of the population skewed toward KLRG 1 hi $\mathrm{CXCR}_{3}{ }^{\text {hi }}$. Our results indicate that at the peak of the immune response in $\mathrm{LCMV}^{\mathrm{Arm}}$ acute infection model, deficiency in NFAT1 or NFAT2 results in distinct $\mathrm{CD}^{+}{ }^{+} \mathrm{T}$ cell differentiation outcomes: NFAT1 controls proper effector cell generation while NFAT2 regulates memory population formation.

To determine if the phenotype observed in the different NFAT deficient mice is sustained to a memory time point, we analyzed effector and memory population in WT, NFAT1 KO, NFAT2 TKO and NFAT1/2 DKO mice 30 days p.i. We found a higher percentage of $\mathrm{H}_{2} \mathrm{D}^{\mathrm{b}}-\mathrm{GP} 33-41^{+} \mathrm{CD}^{+} \mathrm{T}$ cells in NFAT1 KO mice while NFAT1/2 DKO mice showed a trend of reduced frequency and significant decreased total numbers of $\mathrm{H}_{2} \mathrm{D}^{\mathrm{b}}-\mathrm{GP} 33-41$ specific CTLs compared to WT controls (Figures 2A,B, S2B-D). As expected, in WT mice, over $60 \%$ of the WT H2D ${ }^{\mathrm{b}}-\mathrm{GP} 33-$ 41 specific $\mathrm{CD}^{+} \mathrm{T}$ cells express the memory marker CD127, of which only around $25 \%$ retain KLRG1 expression suggesting the formation of a stable memory population (Figures 2C,D). Consistent with what we observed at the peak of the immune response on day 8 , we found a significant further expansion of the memory population in NFAT1 KO mice on day 30 postinfection. Similarly, NFAT2 TKO mice displayed a reduction in memory $\left(\mathrm{CD} 127^{\text {hi }} \mathrm{KRLG}^{\mathrm{lo}}\right.$ ) cells, and an overall increase in KLRG1-expressing cells, particularly KLRG1 ${ }^{\text {hi }}$ CD $127^{\text {hi }}$ subset, compared to WT controls (Figures 2C,D). Notably, in NFAT1/2 DKO mice, we detected a reduction of CD127 single-positive and an increase in KLRG1 single-positive cells compared to other groups, suggesting a delayed transition to a memory phenotype. Similar phenotypic changes were also observed in the expression of CXCR3 (Figures 2C,D). Altogether, NFAT1 and NFAT2 differentially promote $\mathrm{CD}^{+}{ }^{+} \mathrm{T}$ cell differentiation into effector and memory population, respectively, and double deficiency resulted in a reduced antigen-specific CTL population. Our results suggest that NFAT1 and NFAT2 not only play a role in $\mathrm{T}$ cell activation but are also crucial for driving proper $\mathrm{CD} 8^{+}$ T cell commitment potential.

\section{Cell-Intrinsic Effect in the Generation of Effector And Memory Responses Mediated by NFAT Family Members}

Given that NFAT1 germline KO mice, NFAT2 T cell knockout mice and NFAT1/2 DKO mice were used, the differences in the effector and memory CTL differentiation could be due to cell intrinsic or extrinsic effects. To address this, we performed a mixed bone marrow chimera transfer experiment (Figures 3A,B, S3A-D). WT bone marrow cells carrying CD45.1 marker were mixed in a 1:1 ratio with WT, NFAT1 KO, NFAT2 TKO, or NFAT1/2 DKO bone marrow cells carrying CD45.2 marker, and co-transferred to lethally irradiated CD45.1 recipient mice. After 6 weeks, bone marrow reconstituted mice were infected with LCMVArm and analyzed for the generation of effector and memory populations on day 8 post-infection. While there are no differences in total splenocytes or the percentage of $\mathrm{H} 2 \mathrm{D}^{\mathrm{b}}$ GP33-41 specific CD45.1 CTLs among the different groups (Figures S3A,B), mice receiving NFAT1/2 DKO bone marrows showed a trend of decreased $\mathrm{H}_{2} \mathrm{D}^{\mathrm{b}}-\mathrm{GP} 33-41$ specific CTLs in the CD45.2 compartment compared to the control cells, similar to what we have observed in the germline $\mathrm{KO}$ mice. We analyzed the effector and memory $\mathrm{CD}^{+} \mathrm{T}$ cells differentiation by measuring KLRG1 and CD127 expression in both CD45.1 and CD45.2 population (Figures 3B, S3D). We found that cells lacking NFAT1 were skewed toward a memory CTL population, cells lacking NFAT2 showed higher effector memory cells, and cells with NFAT1/2 double deficiency displayed an additive effect (Figures 3B, S3D). In addition, we adoptively transferred NFATdeficient naïve P14 TCR $\alpha^{-/-}$CTLs into congenic mice followed by LCMV Arm infection (Figures 3C,D, S3E,F). Similar altered effector and memory differentiation was found upon NFAT deficiency (Figures 3C,D, S3E,F). Thus, these results indicate the NFAT1 and NFAT2 regulate CTL differentiation in a cell intrinsic manner.

\section{NFAT1 Deficiency Results in Reduced Effector Function, Which Is Further Compromised Upon Compound NFAT2 Deficiency}

To assess if the abnormal $\mathrm{CD}^{+} \mathrm{T}$ cell differentiation upon deficiency of distinct NFAT family members also results in further transcriptional and functional changes, we initially determined the expression of two transcription factors Tbet and Eomes, which have been referred to as master regulators of CTL differentiation controlling the generation of effector and memory cells, respectively (34-36), on both day 8 and 30 postLCMV infection (Figure 4). We found that Tbet expression was significantly reduced in NFAT2 TKO as well as NFAT1/2 DKO mice, with a slight, but not statistically different decrease in NFAT1 KO mice on day 8 p.i (Figures 4 A,B). On the contrary, Eomes expression was significantly increased in NFAT1/2 DKO, and showed a consistent trend toward an increase, although not statistically significant, in NFAT2 $\mathrm{TKO} C D 8^{+} \mathrm{T}$ cells compared to WT controls. To delineate the relative expression between these two transcription factors, we calculated the fold change of Eomes vs. Tbet expression (using MFI) relative to WT cells (Figure 4B). CTLs lacking NFAT2 showed a slight increase in the Eomes:Tbet ratio, while cells with NFAT1 and NFAT2 double deficiency displayed an average of more than 5 -fold increase in Eomes:Tbet compared to WT controls (Figure 4B). This dysregulated Eomes:Tbet expression was observed irrespective of the subpopulation analyzed (effector or memory cells based on KLRG1 and CD127 expression), and thus is not due to differences in frequencies of effector or memory CTLs (data not shown). Similar changes in Eomes:Tbet ratio were observed on day 30, a time point in which Tbet expression is reduced due to a memory transition (Figures 4C,D). The altered Tbet vs. Eomes ratio in NFAT1/2 DKO mice was a result of not only diminished Tbet but also increased Eomes expression (Figures 4B,D). However, at this time point, single NFAT deficiency did not show significant differences in expression of these two transcription factors (Figure 4D). Our results suggest that NFAT transcription factors regulate expression of Tbet and Eomes in vivo. This is in fact consistent with the presence of direct NFAT1, and to a lesser 


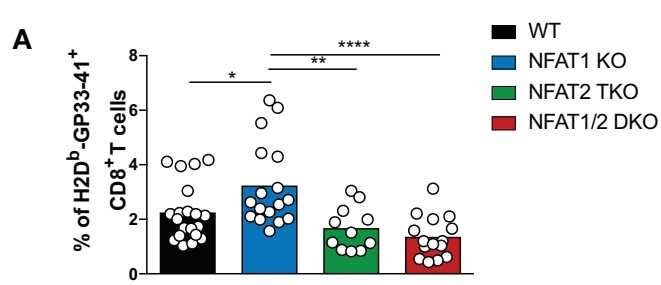

B
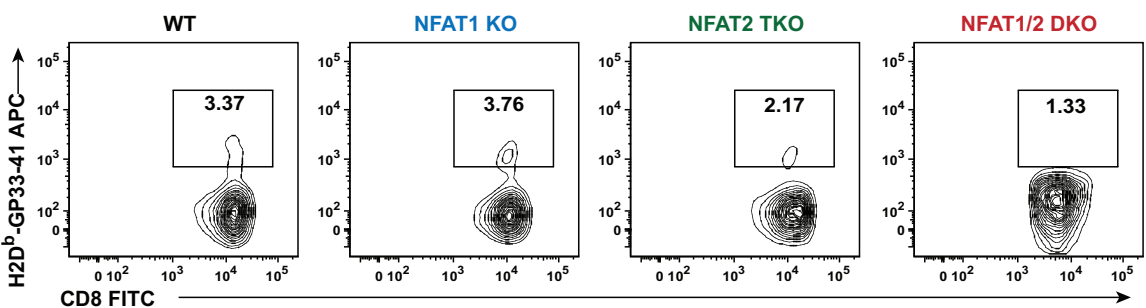

C
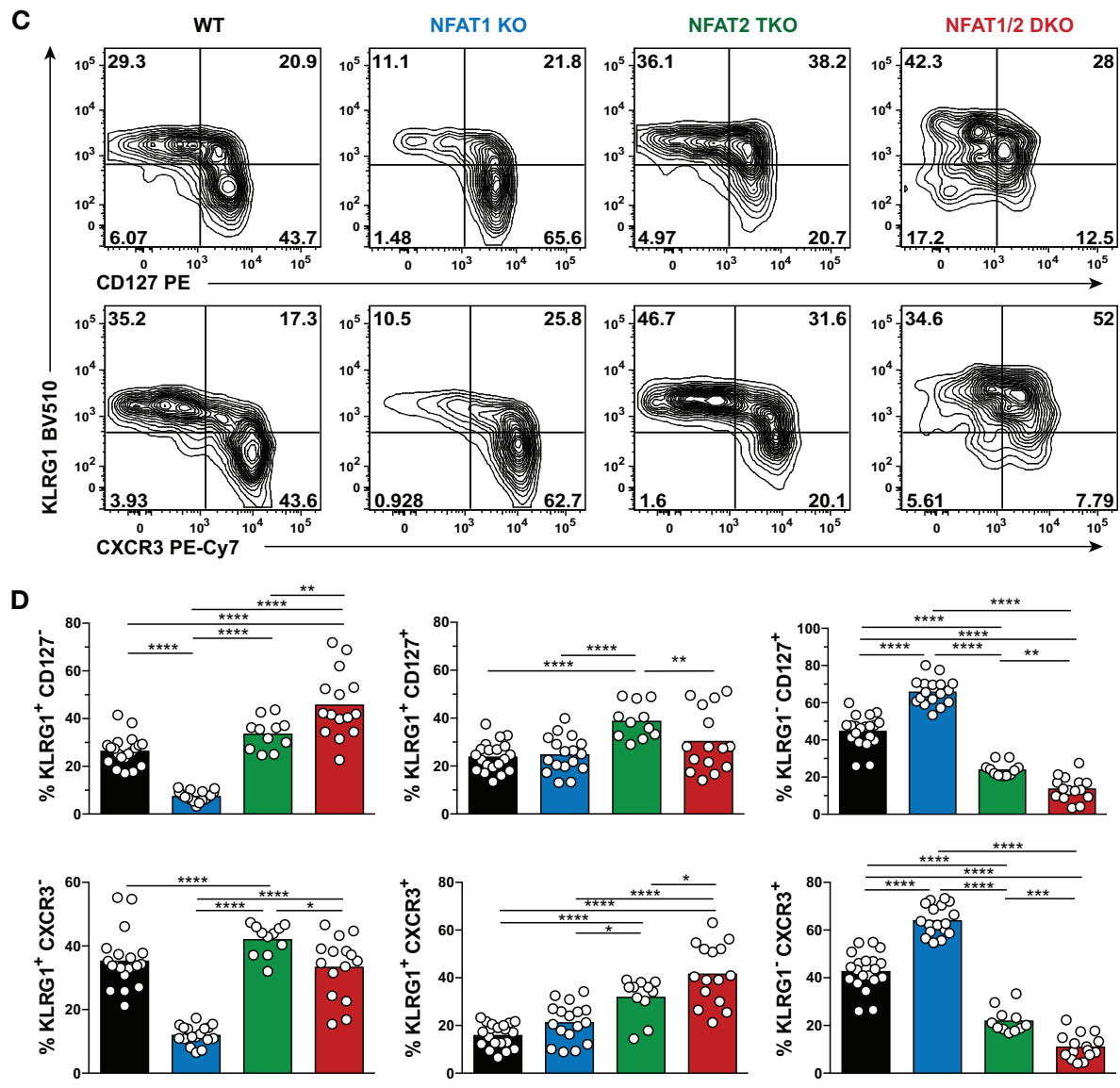

FIGURE 2 | Dysregulated CD8 ${ }^{+}$T cell differentiation in NFAT-deficient mice is sustained during memory response in vivo. Mice were infected with LCMV Arm (2 $\times$ $10^{5}$ PFU/mouse) i.p. Spleens were harvested 30 days post-infection and CD8 ${ }^{+} \mathrm{T}$ cells were phenotypically characterized. (A,B) Frequency of H2D ${ }^{\mathrm{b}}$-gp33-41 ${ }^{+}$ ( $\mathrm{LCMV}$-specific) cells analyzed on $\mathrm{CD}^{+} \mathrm{CD}^{-} \mathrm{B} 220^{-}$cells. A representative contour plot is shown in (B) and the combined data from three independent

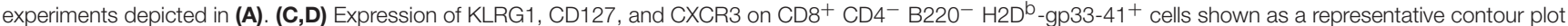
(C) and pooled data from three independent studies (D). Statistical analysis was done using non-paired One-Way ANOVA followed by Tukey's multiple comparisons. ${ }^{\star} p \leq 0.05,{ }^{* *} p \leq 0.01,{ }^{\star * \star} p \leq 0.001,{ }^{* \star * *} p \leq 0.0001$.

extent NFAT2, binding in both Tbx21 and Eomes loci as shown using previously published ChIP-seq data $(27,37)$ (Figure S4).

To determine the impact of NFAT deficiency on CTL function, we initially determined cytokine production in antigen-specific
$\mathrm{CD}^{+} \mathrm{T}$ cells after ex vivo stimulation with PMA and ionomycin (Figures 5A,B). The percentage of CTLs producing both IFN$\gamma$ and TNF- $\alpha$ were reduced in all NFAT-deficient cells, with NFAT1/2 double deficient cells displaying almost complete lack 
A

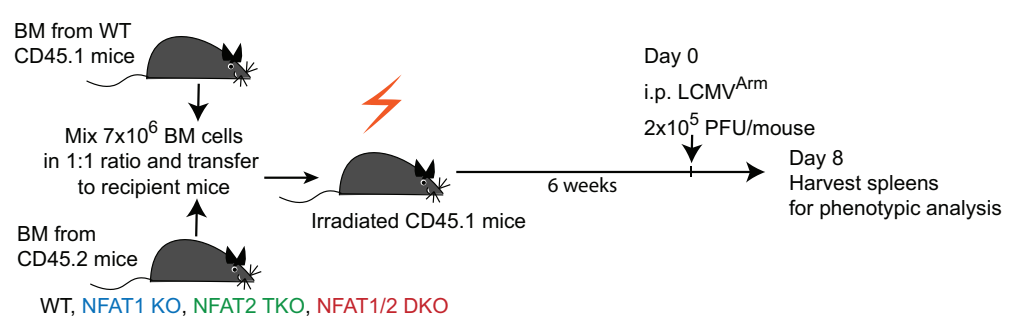

B
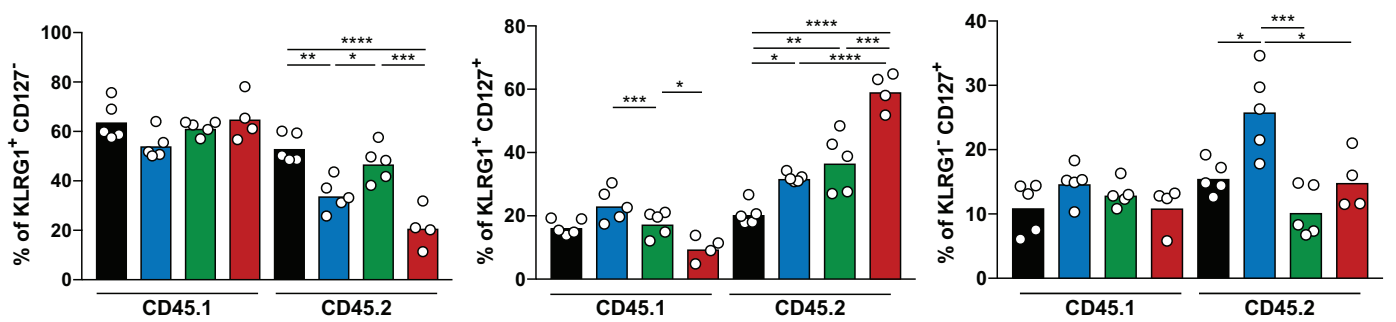

C

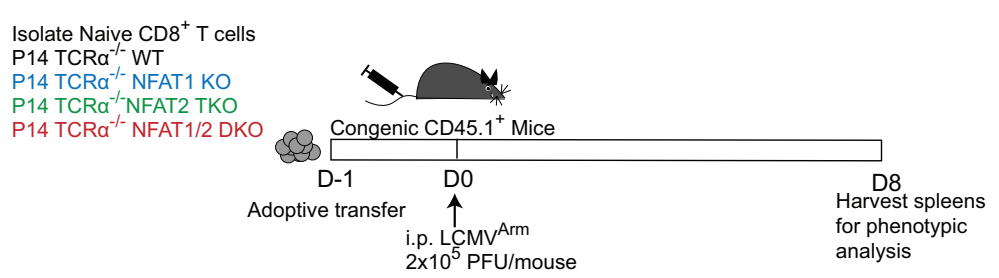

D
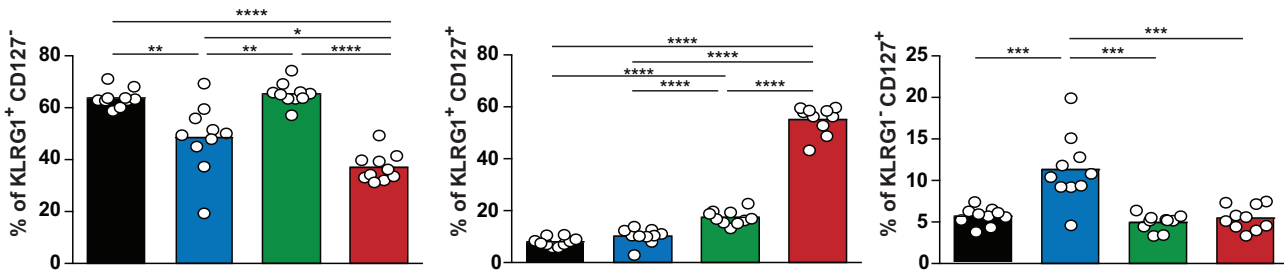

FIGURE 3 | Cell-intrinsic regulation of CD8 ${ }^{+}$T cell differentiation by NFAT1 and NFAT2. (A,B) Mixed bone marrow chimera mice were generated by transferring into lethally irradiated CD45.1 mice a mix (1:1 ratio) of CD45.1 WT bone marrow cells with CD45.2 WT or NFAT-deficient bone marrow cells. Six weeks after reconstitution, mice were infected with LCMV Arm $\left(2 \times 10^{5} \mathrm{PFU} /\right.$ mouse) i.p. Spleens were harvested on day 8 after infection, and phenotypic characterization of CD $8^{+} \mathrm{T}$ cells was performed. (A) Schematic representation of the experimental design. (B) Expression of KLRG1 and CD127 was determined on antigen-specific $\left(\mathrm{H}_{2} \mathrm{D}^{\mathrm{b}}\right.$-gp33-41 $\left.{ }^{+}\right)$ $\mathrm{CD}^{+} \mathrm{T}$ cells in CD45.1 and CD45.2 compartments. A representative experiment out of two is shown. (C,D) P14 TCR transgenic Tcra ${ }^{-1-}$ CD8 ${ }^{+}$T cells from WT or NFAT-deficient mice were adoptively transferred into CD45.1 congenic mice. One day later, mice were infected with LCMV Arm ( $2 \times 10^{5}$ PFU/mouse) i.p. Spleens were harvested on day 8 after infection, and phenotypic characterization of adoptively transferred CD8 ${ }^{+} \mathrm{T}$ cells was performed. (C) Schematic representation of experimental design. (D) Expression of KLRG1 and CD127 was determined on adoptively transferred P14 cells as combined data from two independent experiments. Statistical analysis was done using non-paired One-Way ANOVA followed by Tukey's multiple comparisons (B) or student $T$-test (D). ${ }^{*} p \leq 0.05,{ }^{* \star} p \leq 0.01,{ }^{\star \star *} p \leq$ $0.001,{ }^{* * * *} p \leq 0.0001$

of cytokine production compared to WT controls both on day 8 and 30 (Figures 5A,B). Given that NFAT deficiency results in defective cytokine production, and Eomes levels are increased, which is also characteristic of exhausted cells (38), we hypothesized that these mice were unable to properly control the viral infection. For this purpose, we determined serum viral load in our experimental animals both on day 8 and 30 (Figure 5C). We observed that NFAT1/2 DKO mice were unable to control acute LCMV infection and the viral load increased over time, suggesting that NFATs are crucial for eliciting a proper immune response preventing viral persistence. This is consistent with a previous publication in which mice lacking both STIM1 and STIM2, which are upstream of NFAT signaling, were reported to have viral reoccurrence in the serum upon acute LCMV infection (39). Thus, our results pinpoint NFATs, within the calcium signaling pathways, as vital regulators of CTL function. Moreover, we observed a positive correlation between the viral load and the percentage of KLRG $1^{\text {hi }} \mathrm{CD} 127^{\text {lo }}$ population suggesting that a delayed transition to a memory phenotype is associated with viral persistence (Figure 5D).

To further evaluate the role of NFAT members in CTL function, we utilized an in vitro antigen-specific cytotoxicity assay (Figures 5E,F, S5A-C). For this purpose, WT or NFATdeficient $\mathrm{P} 14^{+}$TCR transgenic naïve $\mathrm{T}$ cells were activated and 


\section{Day 8}
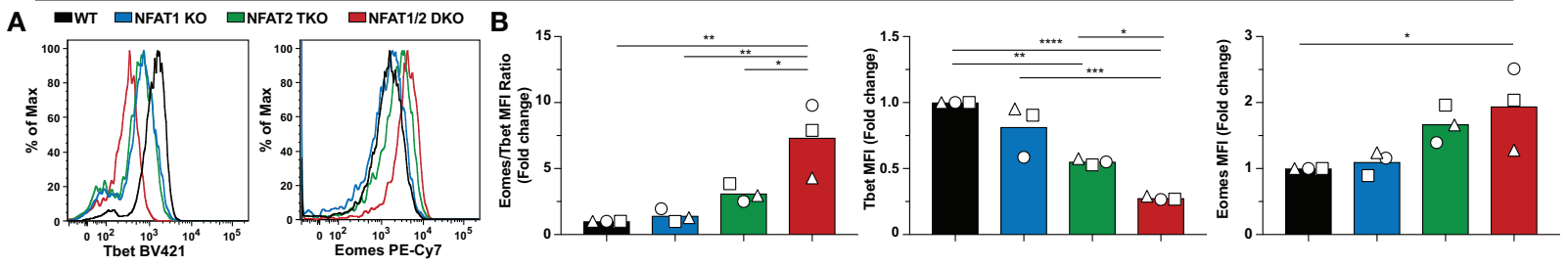

Day 30
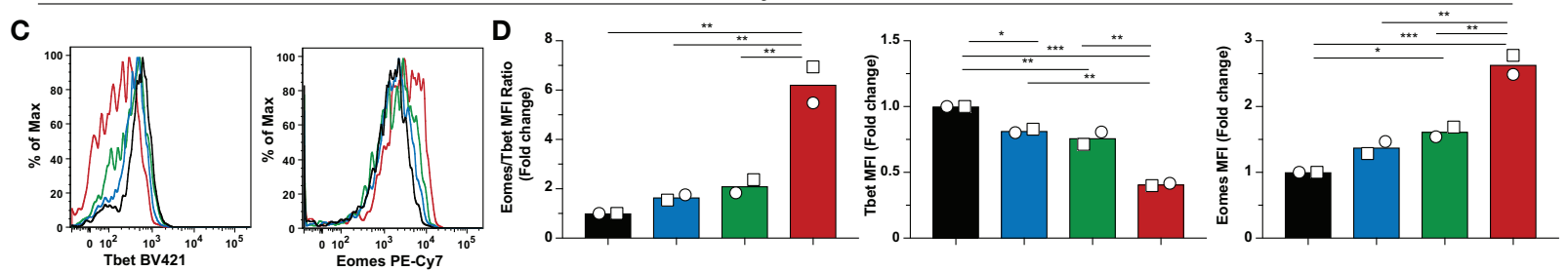

FIGURE 4 | NFAT1 and NFAT2 regulate Tbet and Eomes expression. Expression of Tbet and Eomes was determined on antigen-specific cells from day 8 and 30 experiments depicted in Figures 1, 2. A representative histogram showing Tbet and Eomes MFI is shown on $\mathrm{H}_{2} \mathrm{D}^{\mathrm{b}}-\mathrm{gp} 33-41^{+} \mathrm{CD}^{+} \mathrm{T}$ cells from day 8 -infected mice (A) and day 30 -infected mice (C). Eomes and Tbet MFI fold change ratio as well as the fold change relative to WT mice was calculated by comparing the average Eomes or Tbet MFI fold change from different genotypes in each individual experiment on day8 (B) and day 30 (D). Statistical analysis was done using non-paired One-Way ANOVA followed by Tukey's multiple comparisons. ${ }^{*} p \leq 0.05,{ }^{* *} p \leq 0.01,{ }^{* * *} p \leq 0.001,{ }^{* * * *} p \leq 0.0001$.

differentiated into memory-like CTLs, as previously described (30). These cells were then incubated at different ratios with parental breast cancer cell line EO771 expressing GFP (as negative controls) or EO771-GFP cells expressing GP33-41 (target cells) for $12 \mathrm{~h}$. Cytotoxicity was determined as the frequency of $\mathrm{CD}^{-} \mathrm{GFP}^{-}$cells. We did not observe any significant differences in antigen-specific killing between NFAT2deficient and WT cells at the different ratios, however, cells lacking only NFAT1 or both NFAT1 and NFAT2 showed reduced killing ability (Figure 5F). To further determine the mechanism behind this reduced cytotoxicity, we measured the expression of cytokines or lytic molecules. We found a reduction in Prf1, Ifng, and Il2 mRNA levels in cells with NFAT1 deficiency (either single KO or NFAT1/2 DKO cells) (Figure S5D). Moreover, we also observed a reduction in IFN$\gamma$, IL-2, and TNF- $\alpha$ cytokine production upon restimulation of these NFAT1-deficient memory-like CTLs compared to WT controls (Figures S5D-F). Thus, our data suggests that NFAT1 is mainly responsible for proper effector CTL differentiation and function, which is further strengthen upon NFAT2 deficiency.

\section{DISCUSSION}

NFAT family members have redundant and distinct (sometimes even opposite) roles in lymphocytes development and function. Studies performed in vitro have demonstrated the requirement of different NFATs in CTL cytokine production but their roles in $\mathrm{CD}^{+} \mathrm{T}$ cell differentiation has yet to be determined in vivo (27). In our study, we found that NFAT1 and NFAT2, despite showing similar DNA binding motif specificity and belonging to the same transcription factor family, distinctively regulate $\mathrm{CD} 8^{+} \mathrm{T}$ cell differentiation in vivo. NFAT1 is needed to generate a proper $\mathrm{CD}^{+} \mathrm{T}$ cell effector population whereas NFAT2 is required for promoting memory CTL formation, indicating distinct and even opposing roles in $\mathrm{CD}^{+} \mathrm{T}$ cell differentiation. Compound deletion of both NFAT1 and NFAT2 in CTLs resulted in a significant increase in effector memory cells (expressing high levels of both KLRG1 and CD127) suggesting a delayed transition to memory cells, and a possible additive effect upon deficiency of these two transcription factors. NFAT1/2 DKO antigen-specific $\mathrm{CD}^{+} \mathrm{T}$ cells are significantly less compared to WT counterparts at the peak of the immune response, suggesting an impaired proliferation, which is in accord with NFAT controlling cellcycle entry and proliferation of activated T cells (40). However, CTLs lacking either NFAT1 or NFAT2 are sustained differently upon LCMV ${ }^{\text {Arm }}$ infection: NFAT1 deficiency led to an increased CD $44^{\text {hi }} \mathrm{CD}^{+}$population in contrast to lack of NFAT2, which resulted in reduced $\mathrm{CD} 44^{\text {hi }} \mathrm{CD}^{+}$cells compared to WT controls. Our data is in line with a recent report where expression of NFAT2 in Store-Operated Calcium Entry (SOCE)-deficient T cells restores T cell proliferation in vivo (40). Similarly, a previous report showed that NFAT1 represses cell proliferation whereas NFAT2 promotes cell proliferation in NIH 3T3 cells (41).

NFAT deficiency results in dysregulated expression of Tbet and Eomes, two essential transcription factors that can determine $\mathrm{CD}^{+} \mathrm{T}$ cell fate commitment. While single NFAT deficiency had an increased Eomes:Tbet ratio, cells lacking both NFAT1 and NFAT2 showed the highest Eomes:Tbet ratio. Both NFAT1 and NFAT2 have been shown to directly bind to two regulatory elements in Tbx21 loci, one $11 \mathrm{~kb}$ upstream and another one in the intronic region, which could account for the decrease in Tbet expression upon NFAT deficiency (37) (Figure S4). NFAT1 and NFAT2 also bind to Eomes regulatory elements. Other transcriptional regulators could also compete for NFAT binding and/or Eomes expression regulation. Eomes expression has been shown to be upregulated in exhausted $\mathrm{CD}^{+} \mathrm{T}$ cells during chronic infections and cancer (2); mice with dual deficiency 
A
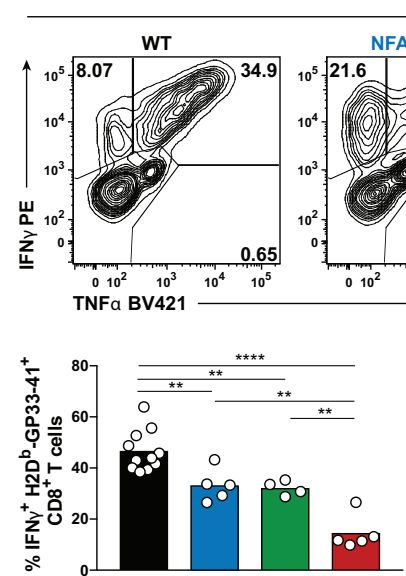

B
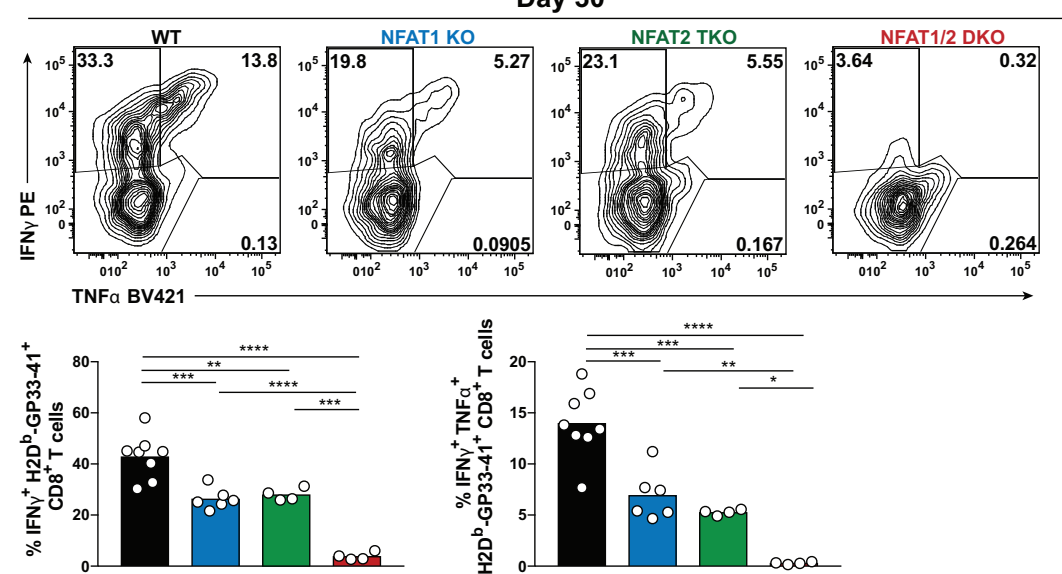

C

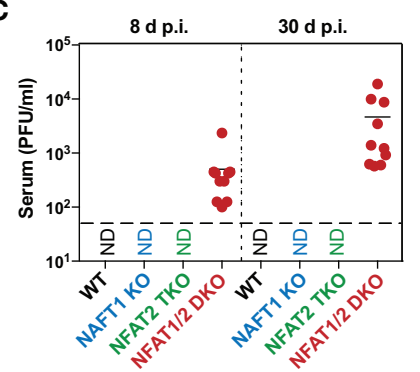

E

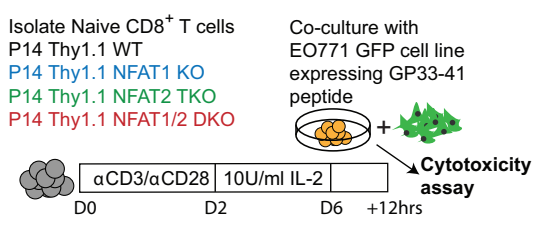

Day 8
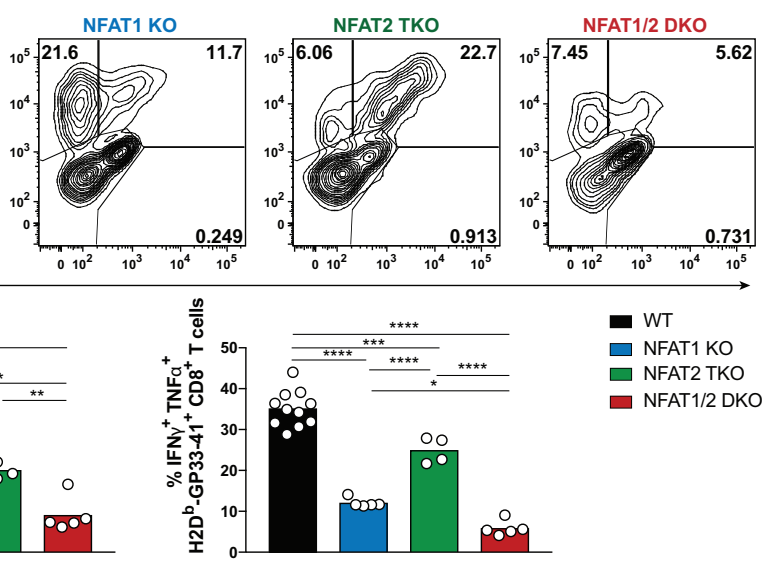

Day 30

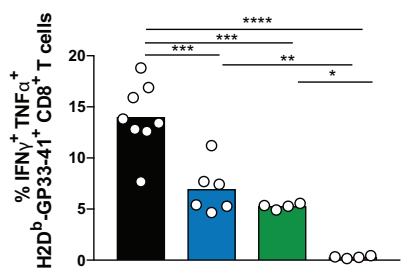

D

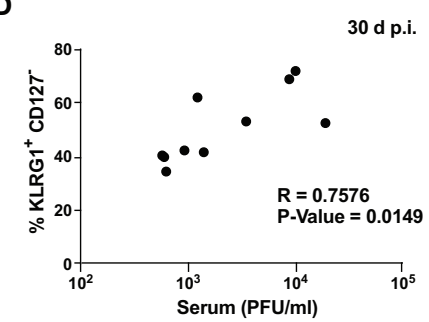

$\mathbf{F}$

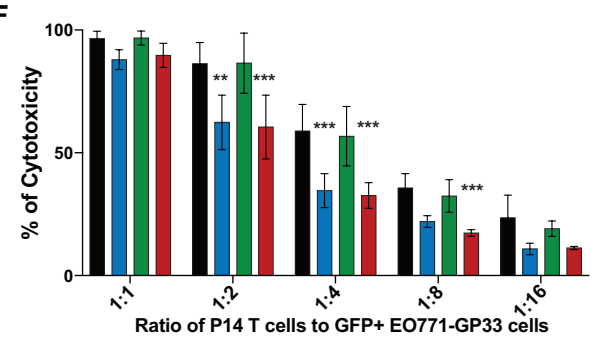

FIGURE 5 | NFAT1 and NFAT2 differentially contribute to CTLs' effector function. (A,B) Cytokine production upon re-stimulation of total splenocytes was determined on antigen-specific cells from day 8 and 30 experiments depicted in Figures 1, 2. Expression of IFN $\gamma$ and TNF $\alpha$ is shown in $\mathrm{H}_{2} \mathrm{D}^{\mathrm{b}}-\mathrm{gp} 33-41^{+} \mathrm{CD} 8^{+} \mathrm{T}$ cells from day 8 (A) and day 30 (B) infections analyzed by One-Way ANOVA. (C) Viral titers from serum of each individual mouse collected from day 8 and 30 experiments

(Figures 1, 2) was determined by plaque assay as Plaque Forming Units (PFU) per ml of serum. N.D., not detectable. (D) Spearman non-parametric correlation 
FIGURE 5 | between percentage of KLRG1+ CD127- antigen-specific cells from NFAT1/2 DKO mice 30d post-infection, and viral titers in serum (PFU/ml) $(p-V a l u e=$ $0.0149, R=0.7576)$. (E,F) In vitro-cultured memory-like P14 TCR transgenic T cells were incubated with EO771-GFP gp33-41+ target cells in series dilution for $12 \mathrm{~h}$. The percentage of $\mathrm{GFP}^{+}$tumor cells was determined, and the percentage of cytotoxicity calculated based on $\mathrm{CD}^{-}{ }^{-} \mathrm{GFP}^{-}$cells. The data shows the mean $+/-\mathrm{SD}$ from three independent experiments, and was analyzed by Two-Way ANOVA followed by Dunnett comparisons ${ }^{*} p \leq 0.05,{ }^{* *} p \leq 0.01,{ }^{* * *} p \leq 0.001,{ }^{* * * *} p \leq 0.0001$.

in NFAT1 and NFAT2 are unable to clear LCMV even in an acute infection model, and similarly express the highest Eomes levels. This viral persistence has also been observed in mice with dual deficiency of STIM1 and STIM2, which are upstream of NFAT signaling pathway. Moreover, these Stim $1^{-/-} \mathrm{Stim} 2^{\mathrm{fl} / \mathrm{fl}}$ $\mathrm{CD}_{4} \mathrm{Cre}^{+}$mice also displayed similar $\mathrm{CD} 8^{+} \mathrm{T}$ cell differentiation defects as observed in the absence of both NFAT1 and NFAT2 (39). The viral persistence also correlates with a significant decrease in frequency of cells recognizing the immunodominant $\mathrm{NP}_{396-404}$ epitope, suggesting chronic antigen stimulation and exhaustion of CTLs in these mice $(29,42)$. The positive correlation between viral titers and KLRG $1^{\text {hi }} \mathrm{CD} 127^{\text {lo }}$ population on day 30 again echoes chronic antigen stimulation. Given that expression of inhibitory receptors associated with exhaustion are directly regulated by NFAT family members (27), the assessment of exhaustion cannot be determined using these markers. Our phenotypic analysis in germline $\mathrm{KO}$ mice was also confirmed using P14 adoptive transfer and mixed bone marrow chimera experiments, demonstrating that NFAT transcription factors regulate CTL differentiation in a cell-intrinsic fashion.

NFAT1, but not NFAT2, controls effector CTL differentiation and cytotoxicity function. Our results show that cells lacking NFAT1 have an enhanced memory CTL commitment in vivo, and show decreased cytotoxicity against mammary carcinoma cells expressing cognate antigen. On the contrary, NFAT2-deficient cells showed increased terminal effector CTL commitment in vivo and normal cytotoxicity function compared to WT counterparts. Surprisingly, it has been recently reported that NFAT2 control cytotoxicity in $\mathrm{CD} 8^{+} \mathrm{T}$ cells in a study utilizing MHC mismatch killing of MOPC 315 plasmacytoma cells and A20J cells (37). Our in vitro killing assay is antigen-specific, which resembles more of CTL in vivo function compared to MHC mismatch-induced killing. Another report recently found a role for NFAT2 in antitumor function by controlling advancedstage non-small cell lung cancer (NSCLC); regional NFAT2 expression correlated with tumor prognosis (43). To support their argument, Heim et al. deleted NFAT2 in both $\mathrm{CD}_{4}^{+}$and $\mathrm{CD}^{+}{ }^{+} \mathrm{T}$ cells which resulted in severe tumor development. Given that NFAT2 is essential for supporting T cell proliferation (40), the loss of tumor control could be due to a reduction in $\mathrm{T}$ cell numbers. Moreover, a defect in both $\mathrm{CD} 4^{+}$and $\mathrm{CD}^{+} \mathrm{T}$ cell function was observed, which impedes the understanding of cell-intrinsic effects. Therefore, the differences in NFAT1 and NFAT2 deficient CTL killing capacity need further illustration in vivo. Additionally, the dysregulated effector and memory $\mathrm{CD} 8^{+}$ $\mathrm{T}$ cell differentiation upon NFAT1 and NFAT2 deficiency could also have differential effects in the effector and memory phase. Nevertheless, our ex vivo and in vitro stimulation of NFAT deficient $\mathrm{CD}^{+} \mathrm{T}$ cells recapitulate previous findings that NFAT1 mainly regulates production of IFN- $\gamma$ while other NFATs might have compensatory roles upon re-stimulation in vitro (27).
The early transcriptional regulation of $\mathrm{CD}^{+} \mathrm{T}$ cell differentiation that set the epigenetic tone for gene expression prior to the proliferative burst is not fully understood (44). BATF and IRF4 have also been shown to function as pioneer factors required for CTL differentiation $(13,15)$. However, recently Pipkin and colleagues demonstrated that Runx3 functions upstream of these factors, working as a pioneer transcription factor that induces chromatin accessibility of cis-regulatory landscapes crucial for memory CTL formation (18). NFATs are among the primary regulators downstream of TCR signaling, being activated and translocated to the nucleus within minutes of TCR stimulation (23), and are therefore expected to have profound roles during priming. This idea is consonant with the loss of chromatin accessible regions containing NFAT binding sites in Runx3 knockout $\mathrm{CD}^{+} \mathrm{T}$ cells within the first $24 \mathrm{~h}$ of stimulation (18). Furthermore, it has also been suggested that NFATs directly regulate IRF4 expression and form an IRF4NFAT-BATF transcriptional circuit (45). Similarly, NFAT factors have also been reported to control expression of transcription factor HIF1a as well as metabolic genes, pathways that can also affect $\mathrm{CD}^{+} \mathrm{T}$ cell fate upon activation (40,46-48). Thus, NFAT family members could control the transcriptional induction of several genes that can coordinately regulate CTL differentiation in vivo, suggesting that they could function as non-redundant pioneer transcription factors driving effector and memory CTL commitment. Future work on better understanding the role of NFAT family members can help elucidate these distinct mechanisms.

We have identified that NFAT1 and NFAT2 have opposite functions in CTL differentiation. These differential roles of transcription factors belonging to the same family have been explored. For example, Id2 is essential for generating SLEC population whereas Id3 is crucial for long-lived memory CTLs (10). IL-10-IL-21-STAT3 axis promotes $\mathrm{CD}^{+} \mathrm{T}$ cell memory differentiation and preserve cell stemness (49), while IL-12STAT4 axis downregulates TCF1 expression to promote effector cell differentiation (50). Another example is the Egr family members, which also display opposing functions: Egr-2 and-3 play as TCR-induced negative regulators of $\mathrm{T}$ cell function, whereas Egr-1 promotes $\mathrm{T}$ cell function $(51,52)$. While the induction of Egr-2 and Egr-3 expression by NFAT can be independent of AP-1 (27), Egr-1 requires both NFAT and AP-1 to induce its expression in $\mathrm{CD} 4^{+} \mathrm{T}$ cells (53).

NFAT1 and NFAT2 could distinctly control gene expression, driving CTL differentiation through distinct mechanisms. Three possible mechanisms are: (i) the structural differences between NFATs, especially in the transactivation region (TAD) domain (54); (ii) the timing of activation, where NFAT2 short isoform expression is induced by NFAT1 activation (55); (iii) the unique binding partners of different NFATs even in different NFAT isoforms. Recent mass spectrometric analysis showed a 
higher number of NFAT1 unique associated proteins compared to NFAT2, suggesting these family members could distinctly regulate gene expression to induce CTL differentiation by cooperating with different transcription partners (56). The challenge of understanding the mechanism behind the distinct function of NFAT members should be further investigated during early $\mathrm{T}$ cell activation. How NFATs cooperate with other transcriptional regulators immediately after priming to form the chromatin landscape that eventually leads to effector and memory differentiation still remains unclear. Nonetheless, our work demonstrates the differential regulation of $\mathrm{CD}^{+} \mathrm{T}$ cell differentiation by NFAT1 and NFAT2 in acute viral infection, and provides a framework for understanding the roles of NFATs in early priming, effector and memory $\mathrm{CD} 8^{+} \mathrm{T}$ cell function.

\section{AUTHOR CONTRIBUTIONS}

TX and GM designed the experiments and wrote the article. TX performed experiments, analyzed and plotted the data. AK maintained the mouse colony and helped with in vivo experiments. GM supervised the project.

\section{REFERENCES}

1. Swann JB, Smyth MJ. Immune surveillance of tumors. J Clin Invest. (2007) 117:1137-46. doi: 10.1172/JCI31405

2. Paley MA, Kroy DC, Odorizzi PM, Johnnidis JB, Dolfi DV, Barnett BE, et al. Progenitor and terminal subsets of $\mathrm{CD}^{+}{ }^{+} \mathrm{T}$ cells cooperate to contain chronic viral infection. Science (2012) 338:1220-5. doi: 10.1126/science.1229620

3. Wherry EJ, Ahmed R. Memory CD8 T-cell differentiation during viral infection. J Virol. (2004) 78:5535-45. doi: 10.1128/JVI.78.11.5535-5545.2004

4. Joshi NS, Cui W, Chandele A, Lee HK, Urso DR, Hagman J, et al. Inflammation directs memory precursor and short-lived effector CD8(+) T cell fates via the graded expression of T-bet transcription factor. Immunity (2007) 27:281-95. doi: 10.1016/j.immuni.2007.07.010

5. Fowler CC, Pao LI, Blattman JN, Greenberg PD. SHP-1 in T cells limits the production of CD8 effector cells without impacting the formation of long-lived central memory cells. J Immunol. (2010) 185:3256-67. doi: 10.4049/jimmunol.1001362

6. Herndler-Brandstetter D, Ishigame H, Shinnakasu R, Plajer V, Stecher C, Zhao J, et al. KLRG1(+) Effector CD8(+) T cells lose KLRG1, differentiate into all memory $\mathrm{T}$ cell lineages, and convey enhanced protective immunity. Immunity (2018) 48:716-29 e8. doi: 10.1016/j.immuni.2018.03.015

7. Nayar R, Schutten E, Jangalwe S, Durost PA, Kenney LL, Conley JM, et al. IRF4 regulates the ratio of T-bet to eomesodermin in $\mathrm{CD}^{+} \mathrm{T}$ cells responding to persistent LCMV infection. PLOS ONE (2015) 10:e0144826. doi: 10.1371/journal.pone.0144826

8. Wu T, Ji Y, Moseman EA, Xu HC, Manglani M, Kirby M, et al. The TCF1Bcl6 axis counteracts type I interferon to repress exhaustion and maintain T cell stemness. Sci Immunol. (2016) 1:eaai8593. doi: 10.1126/sciimmunol. aai8593

9. Cannarile MA, Lind NA, Rivera R, Sheridan AD, Camfield KA, Wu BB, et al. Transcriptional regulator Id 2 mediates $\mathrm{CD}^{+}{ }^{+} \mathrm{T}$ cell immunity. Nat Immunol. (2006) 7:1317-25. doi: 10.1038/ni1403

10. Yang CY, Best JA, Knell J, Yang E, Sheridan AD, Jesionek AK, et al. The transcriptional regulators Id2 and Id 3 control the formation of distinct memory CD8 ${ }^{+} \mathrm{T}$ cell subsets. Nat Immunol. (2011) 12:1221-9. doi: $10.1038 /$ ni. 2158

11. Ichii H, Sakamoto A, Kuroda Y, Tokuhisa T. Bcl6 acts as an amplifier for the generation and proliferative capacity of central memory $\mathrm{CD}^{+}$ $\mathrm{T}$ cells. J Immunol. (2004) 173:883-91. doi: 10.4049/jimmunol.17 3.2 .883

\section{ACKNOWLEDGMENTS}

We thank Dr. Anjana Rao (La Jolla Institute) and Matthew Pipkin (The Scripps Research Institute) for providing the NFATdeficient mice strains utilized in this study, Robert Dickinson at Rosalind Franklin University of Medicine and Science Flow Cytometry Facility for help with cell sorting experiments, and the National Institutes of Health (NIH) Tetramer Facility for providing with the LCMV tetramers described in the Materials and Methods section. We are also grateful for Dr. Renata Pereira at Federal University of Rio the Janeiro for her critical reading comments of the manuscript. This study was supported by Rosalind Franklin University of Medicine and Science as well as partially funded by the American Cancer Society Research Scholar Grant 131049-RSG-17-185-01-LIB (to GM).

\section{SUPPLEMENTARY MATERIAL}

The Supplementary Material for this article can be found online at: https://www.frontiersin.org/articles/10.3389/fimmu. 2019.00184/full\#supplementary-material

12. Kallies A, Xin A, Belz GT, Nutt SL. Blimp-1 transcription factor is required for the differentiation of effector CD8(+) T cells and memory responses. Immunity (2009) 31:283-95. doi: 10.1016/j.immuni.2009.06.021

13. Kurachi M, Barnitz RA, Yosef N, Odorizzi PM, DiIorio MA, Lemieux ME, et al. The transcription factor BATF operates as an essential differentiation checkpoint in early effector CD8 ${ }^{+}$T cells. Nat Immunol. (2014) 15:373-83. doi: $10.1038 /$ ni.2834

14. Godeca JB, Cowleyc GS, Barnitza AR, Alkanc O, Rootc DE, Sharpeb AH, et al. Inducible RNAi in vivo reveals that the transcription factor BATF is required to initiate but not maintain $\mathrm{CD}^{+}{ }^{+}$T-cell effector differentiation. Proc Natl Acad Sci USA. (2015) 112:E4968. doi: 10.1073/pnas.1514097112

15. Yao S, Buzo BF, Pham D, Jiang L, Taparowsky EJ, Kaplan MH, et al. Interferon regulatory factor 4 sustains $\mathrm{CD} 8(+) \mathrm{T}$ cell expansion and effector differentiation. Immunity (2013) 39:833-45. doi: 10.1016/j.immuni.2013.10.007

16. Grusdat M, McIlwain DR, Xu HC, Pozdeev VI, Knievel J, Crome SQ, et al. IRF4 and BATF are critical for CD8(+) T-cell function following infection with LCMV. Cell Death Differ. (2014) 21:1050-60. doi: 10.1038/cdd.2014.19

17. Luckey MA, Kimura MY, Waickman AT, Feigenbaum L, Singer A, Park JH. The transcription factor ThPOK suppresses Runx3 and imposes CD4(+) lineage fate by inducing the SOCS suppressors of cytokine signaling. Nat Immunol. (2014) 15:638-45. doi: 10.1038/ni.2917

18. Wang D, Diao H, Getzler AJ, Rogal W, Frederick MA, Milner J, et al. The transcription factor Runx3 establishes chromatin accessibility of cisregulatory landscapes that drive memory cytotoxic $\mathrm{T}$ lymphocyte formation. Immunity (2018) 48:659-674 e6. doi: 10.1016/j.immuni.2018.03.028

19. Muller MR, Rao A. NFAT, immunity and cancer: a transcription factor comes of age. Nat Rev Immunol. (2010) 10:645-56. doi: 10.1038/nri2818

20. Badran BM, Wolinsky SM, Burny A, Willard-Gallo KE. Identification of three NFAT binding motifs in the $5^{\prime}$-upstream region of the human CD3gamma gene that differentially bind NFATc1, NFATc2, and NF-kappa B p50. J Biol Chem. (2002) 277:47136-48. doi: 10.1074/jbc.M206330200

21. Hogan PG, Chen L, Nardone J, Rao A. Transcriptional regulation by calcium, calcineurin, and NFAT. Genes Dev. (2003) 17:2205-32. doi: $10.1101 / \operatorname{gad} .1102703$

22. Chen L, Glover JN, Hogan PG, Rao A, Harrison SC. Structure of the DNAbinding domains from NFAT, Fos and Jun bound specifically to DNA. Nature (1998) 392:42-8.

23. Marangoni F, Murooka TT, Manzo T, Kim EY, Carrizosa E, Elpek NM, et al. The transcription factor NFAT exhibits signal memory during serial $\mathrm{T}$ 
cell interactions with antigen-presenting cells. Immunity (2013) 38:237-49. doi: 10.1016/j.immuni.2012.09.012

24. Martinez GJ, Hu JK, Pereira RM, Crampton JS, Togher S, Bild N, et al. Cutting edge: NFAT transcription factors promote the generation of follicular helper T cells in response to acute viral infection. J Immunol. (2016) 196:2015-9. doi: 10.4049/jimmunol.1501841

25. Dietz L, Frommer F, Vogel AL, Vaeth M, Serfling E, Waisman A, et al. NFAT1 deficit and NFAT2 deficit attenuate EAE via different mechanisms. Eur J Immunol. (2015) 45:1377-89. doi: 10.1002/eji.201444638

26. Hermann-Kleiter N, Baier G. NFAT pulls the strings during $\mathrm{CD}^{+} \mathrm{T}$ helper cell effector functions. Blood (2010) 115:2989-97. doi: 10.1182/blood-2009-10-233585

27. Martinez GJ, Pereira RM, Äijö T, Kim EY, Marangoni F, Pipkin ME, et al. The transcription factor NFAT promotes exhaustion of activated CD8(+) T cells. Immunity (2015) 42:265-78. doi: 10.1016/j.immuni.2015.01.006

28. Ahmed R, Salmi A, Butler LD, Chiller JM, Oldstone MB. Selection of genetic variants of lymphocytic choriomeningitis virus in spleens of persistently infected mice. Role in suppression of cytotoxic T lymphocyte response and viral persistence. J Exp Med. (1984) 160:521-40. doi: 10.1084/jem.160.2.521

29. Wherry EJ, Blattman JN, Murali-Krishna K, van der Most R, Ahmed R. Viral persistence alters CD8 T-cell immunodominance and tissue distribution and results in distinct stages of functional impairment. J Virol. (2003) 77:4911-27. doi: 10.1128/JVI.77.8.4911-4927.2003

30. Pipkin ME, Sacks JA, Cruz-Guilloty F, Lichtenheld MG, Bevan MJ, Rao A. Interleukin-2 and inflammation induce distinct transcriptional programs that promote the differentiation of effector cytolytic T cells. Immunity (2010) 32:79-90. doi: 10.1016/j.immuni.2009.11.012

31. Hikono H, Kohlmeier JE, Takamura S, Wittmer ST, Roberts AD, Woodland DL. Activation phenotype, rather than central- or effector-memory phenotype, predicts the recall efficacy of memory $\mathrm{CD}^{+} \mathrm{T}$ cells. J Exp Med. (2007) 204:1625-36. doi: 10.1084/jem.20070322

32. Groom JR, Luster AD. CXCR3 ligands: redundant, collaborative and antagonistic functions. Immunol Cell Biol. (2011) 89:207-15. doi: $10.1038 /$ icb. 2010.158

33. Olson JA, McDonald-Hyman C, Jameson SC, Hamilton SE. Effector-like $\mathrm{CD} 8(+) \mathrm{T}$ cells in the memory population mediate potent protective immunity. Immunity (2013) 38:1250-60. doi: 10.1016/j.immuni.2013.05.009

34. Intlekofer AM, Takemoto N, Wherry EJ, Longworth SA, Northrup JT, Palanivel VR, et al. Effector and memory CD8 ${ }^{+} \mathrm{T}$ cell fate coupled by T-bet and eomesodermin. Nat Immunol. (2005) 6:1236-44. doi: 10.1038/ni1268

35. Pearce EL, Mullen AC, Martins GA, Krawczyk CM, Hutchins AS, Zediak VP, et al. Control of effector $\mathrm{CD} 8^{+} \mathrm{T}$ cell function by the transcription factor Eomesodermin. Science. (2003) 302:1041-3. doi: 10.1126/science.1090148

36. Popescu I, Pipeling MR, Shah PD, Orens JB, McDyer JF. T-bet: Eomes balance, effector function, and proliferation of cytomegalovirus-specific $\mathrm{CD}^{+} \mathrm{T}$ cells during primary infection differentiates the capacity for durable immune control. J Immunol. (2014) 193:5709-22. doi: 10.4049/jimmunol.14 01436

37. Klein-Hessling S, Muhammad K, Klein M, Pusch T, Rudolf R, Flöter J, et al. NFATc1 controls the cytotoxicity of CD8(+) T cells. Nat Commun. (2017) 8:511. doi: 10.1038/s41467-017-00612-6

38. Wherry EJ, Ha SJ, Kaech SM, Haining WN, Sarkar S, Kalia V, et al. Molecular signature of $\mathrm{CD}^{+} \mathrm{T}$ cell exhaustion during chronic viral infection. Immunity (2007) 27:670-84. doi: 10.1016/j.immuni.2007.09.006

39. Shaw PJ, Weidinger C, Vaeth M, Luethy K, Kaech SM, Feske S. CD4(+) and CD8(+) T cell-dependent antiviral immunity requires STIM1 and STIM2. J Clin Invest. (2014) 124:4549-63. doi: 10.1172/JCI76602

40. Vaeth M, Maus M, Klein-Hessling S, Freinkman E, Yang J, Eckstein $\mathrm{M}$, et al. Store-operated $\mathrm{Ca}(2+)$ entry controls clonal expansion of $\mathrm{T}$ cells through metabolic reprogramming. Immunity (2017) 47:664-79 e6. doi: 10.1016/j.immuni.2017.09.003

41. Lucena PI, Faget DV, Pachulec E, Robaina MC, Klumb CE, Robbs BK, et al. NFAT2 isoforms differentially regulate gene expression, cell death, and transformation through alternative N-terminal domains. Mol Cell Biol. (2016) 36:119-31. doi: 10.1128/MCB.00501-15

42. van der Most RG, Murali-Krishna K, Lanier JG, Wherry EJ, Puglielli MT, Blattman JN, et al. Changing immunodominance patterns in antiviral CD8 T-cell responses after loss of epitope presentation or chronic antigenic stimulation. Virology (2003) 315:93-102. doi: 10.1016/j.virol.2003.07.001

43. Heim L, Friedrich J, Engelhardt M, Trufa DI, Geppert CI, Rieker RJ, et al. NFATc1 promotes antitumoral effector functions and memory CD8(+) T-cell differentiation during non-small cell lung cancer development. Cancer Res. (2018) 78:3619-33. doi: 10.1158/0008-5472.CAN-17-3297

44. Chang JT, Wherry EJ, Goldrath AW. Molecular regulation of effector and memory $\mathrm{T}$ cell differentiation. Nat Immunol. (2014) 15:1104-15. doi: $10.1038 /$ ni.3031

45. Man K, Gabriel SS, Liao Y, Gloury R, Preston S, Henstridge DC, et al. Transcription factor IRF4 promotes CD8(+) T cell exhaustion and limits the development of memory-like $\mathrm{T}$ cells during chronic infection. Immunity (2017) 47:1129-41 e5. doi: 10.1016/j.immuni.2017.11.021

46. Vaeth M, Feske S. NFAT control of immune function: new frontiers for an abiding trooper. F1000Res (2018) 7:260. doi: 10.12688/f1000research.13426.1

47. Vaeth M, Eckstein M, Shaw PJ, Kozhaya L, Yang J, Berberich-Siebelt $F$, et al. Store-operated $\mathrm{Ca}(2+)$ entry in follicular $\mathrm{T}$ cells controls humoral immune responses and autoimmunity. Immunity (2016) 44:1350-64. doi: 10.1016/j.immuni.2016.04.013

48. Walczak-Drzewiecka A, Ratajewski M, Wagner W, Dastych J. HIF-1alpha is up-regulated in activated mast cells by a process that involves calcineurin and NFAT. J Immunol. (2008) 181:1665-72. doi: 10.4049/jimmunol.181.3.1665

49. Cui W, Liu Y, Weinstein JS, Craft J, Kaech SM. An interleukin-21-interleukin10-STAT3 pathway is critical for functional maturation of memory $\mathrm{CD}^{+} \mathrm{T}$ cells. Immunity (2011) 35:792-805. doi: 10.1016/j.immuni.2011.09.017

50. Danilo M, Chennupati V, Silva JG, Siegert S, Held W. Suppression of Tcf1 by inflammatory cytokines facilitates effector CD8 T cell differentiation. Cell Rep. (2018) 22:2107-17. doi: 10.1016/j.celrep.2018.01.072

51. Collins S, Wolfraim LA, Drake CG, Horton MR, Powell JD. Cutting edge: TCR-induced NAB2 enhances $\mathrm{T}$ cell function by coactivating IL-2 transcription. J Immunol. (2006) 177:8301-5. doi: 10.4049/jimmunol.177.12.8301

52. Tussiwand R, Lee WL, Murphy TL, Mashayekhi M, KC W, Albring JC, et al. Compensatory dendritic cell development mediated by BATF-IRF interactions. Nature (2012) 490:502-7. doi: 10.1038/nature11531

53. Collins S, Lutz MA, Zarek PE, Anders RA, Kersh GJ, Powell JD. Opposing regulation of T cell function by Egr-1/NAB2 and Egr-2/Egr-3. Eur J Immunol. (2008) 38:528-36. doi: 10.1002/eji.200737157

54. Mognol GP, Carneiro FR, Robbs BK, Faget DV, Viola JP. Cell cycle and apoptosis regulation by NFAT transcription factors: new roles for an old player. Cell Death Dis. (2016) 7:e2199. doi: 10.1038/cddis.2016.97

55. Zhou B, Cron RQ, Wu B, Genin A, Wang Z, Liu S, et al. Regulation of the murine Nfatc1 gene by NFATc2. J Biol Chem. (2002) 277:10704-11. doi: $10.1074 /$ jbc.M107068200

56. Gabriel CH, Gross F, Karl M, Stephanowitz H, Hennig AF, Weber $\mathrm{M}$, et al. Identification of novel nuclear factor of activated $\mathrm{T}$ cell (NFAT)-associated proteins in T cells. J Biol Chem. (2016) 291:24172-87. doi: 10.1074/jbc.M116.739326

Conflict of Interest Statement: The authors declare that the research was conducted in the absence of any commercial or financial relationships that could be construed as a potential conflict of interest.

Copyright (๑) $2019 \mathrm{Xu}$, Keller and Martinez. This is an open-access article distributed under the terms of the Creative Commons Attribution License (CC BY). The use, distribution or reproduction in other forums is permitted, provided the original author(s) and the copyright owner(s) are credited and that the original publication in this journal is cited, in accordance with accepted academic practice. No use, distribution or reproduction is permitted which does not comply with these terms. 